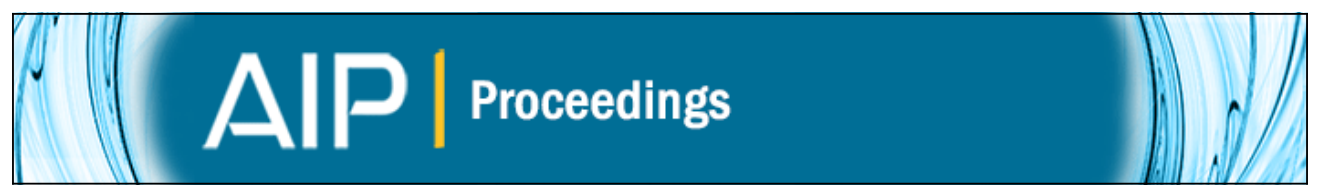

\title{
Line Scaling Effect on Grain Structure for Cu Interconnects
}

Lijuan Zhang, Jay Im, and Paul S. Ho

Citation: AIP Conference Proceedings 1143, 151 (2009); doi: 10.1063/1.3169254

View online: http://dx.doi.org/10.1063/1.3169254

View Table of Contents:

http://scitation.aip.org/content/aip/proceeding/aipcp/1143?ver=pdfcov

Published by the AIP Publishing

\section{Articles you may be interested in}

Cathodic peeling damage of $\mathrm{Cu} 6 \mathrm{Sn} 5$ phase in $\mathrm{Cu} / \mathrm{SnAg} 3.0 \mathrm{Cu} 0.5 / \mathrm{Cu}$ bridge interconnections under current stressing

J. Appl. Phys. 116, 054909 (2014); 10.1063/1.4892365

Grain structure analysis and effect on electromigration reliability in nanoscale $\mathrm{Cu}$ interconnects

Appl. Phys. Lett. 102, 131907 (2013); 10.1063/1.4799484

Synchrotron measurement of the effect of linewidth scaling on stress in advanced Cu/Low- $k$ interconnects

J. Appl. Phys. 106, 053524 (2009); 10.1063/1.3212572

TEM Measurements of Grain Orientation in Nanoscale Cu Interconnects using ACT AIP Conf. Proc. 1143, 166 (2009); 10.1063/1.3169256

Reduction effect of line edge roughness on time-dependent dielectric breakdown lifetime of Cu/low- $\mathrm{k}$ interconnects by using C F 3 I etching J. Vac. Sci. Technol. B 27, 649 (2009); 10.1116/1.3100268 


\title{
Line Scaling Effect on Grain Structure for Cu Interconnects
}

\author{
Lijuan Zhang, Jay Im and Paul S. Ho \\ Laboratory for Interconnect and Packaging, Microelectronics Research Center \\ The University of Texas at Austin, $T X 78712$
}

\begin{abstract}
The effect of line scaling on Cu grain structures has been investigated by using both plan-view and cross-sectional transmission electron microscopy (TEM) techniques. Cu damascene lines with three different line widths of 850,185 and $60 \mathrm{~nm}$ were studied. The plan-view TEM images revealed that the $850 \mathrm{~nm}$ lines had both polycrystalline and bamboo-like grain structures, whereas the 185 and the $60 \mathrm{~nm}$ lines had near bamboo-like structures. Statistical analysis was performed on the grain size distributions for both $185 \mathrm{~nm}$ and $60 \mathrm{~nm}$ lines. The results showed that the $185 \mathrm{~nm}$ lines followed a normal grain growth behavior, while the 60 $\mathrm{nm}$ lines deviated from normal grain growth with excessive small grains at the lower percentile which was attributed to scaling-induced small grain growth. Further analysis by cross-sectional TEM along the $\mathrm{Cu}$ trench line direction revealed that the $850 \mathrm{~nm}$ lines had bamboo-like structures across the thickness while the $185 \mathrm{~nm}$ and the $60 \mathrm{~nm}$ lines showed a combination of bamboo-like and multigrain structures with small grain clusters concentrated at the trench bottom.
\end{abstract}

Keywords: Cu Interconnects, Plan-view TEM, Cross-sectional TEM, Grain, Microstructure.

\section{INTRODUCTION}

Copper has been widely used as interconnect material for high performance ultra-large scale integrated circuits (ULSIs) due to its superior electrical conductivity and robust electromigration (EM) reliability. Through the damascene process, $\mathrm{Cu}$ has been successfully implemented into ULSI chips. Extensive data have been published ${ }^{14}$ on the microstructure of damascene $\mathrm{Cu}$ lines regarding the grain texture and size distribution and their variations with different line widths. Nevertheless, only few results have been reported recently ${ }^{5-8}$ on the microstructures of $\mathrm{Cu}$ lines narrower than $100 \mathrm{~nm}$. For ultra-narrow $\mathrm{Cu}$ lines less than $100 \mathrm{~nm}$ wide, the resistivity was found to increase as the line width scales down. This effect was attributed to the increase in electron scattering caused by the surface, the interface and the grain boundary when the line width is approaching the electron mean free path in $\mathrm{Cu}\left(45 \mathrm{~nm}\right.$ at room temperature $\left.{ }^{5}\right)$. For ultra-narrow $\mathrm{Cu}$ lines, there is a serious reliability concern arising from insufficient grain growth ${ }^{7}$. This can increase the grain boundaries, leading to an increase in resistivity and a degradation of the EM reliability. The degradation in EM lifetime was indeed observed recently for $\mathrm{Cu}$ lines at $90 \mathrm{~nm}$ line width and the effect was attributed to additional fast mass transport along the grain boundaries.

In this paper, we investigated the scaling effect on the grain structure for $\mathrm{Cu}$ lines using transmission electron microscopy (TEM) techniques. The study was performed on $\mathrm{Cu}$ damascene lines of $60 \mathrm{~nm}$ line width fabricated by using a trench filling technique together with $\mathrm{Cu}$ lines with widths of $185 \mathrm{~nm}$ and 850 $\mathrm{nm}$. Microstructures of $\mathrm{Cu}$ lines were examined by using both top-view (plan-view) and side-view (crosssectional) TEM. With the resolution provided by TEM, grains of size smaller than $10 \mathrm{~nm}$ can be readily observed and analyzed. 


\section{EXPERIMENTAL DETAILS}

The $\mathrm{Cu}$ interconnects were fabricated by SEMATECH using standard damascene process. The intermetal dielectric (IMD) material was silicon oxide $\left(\mathrm{SiO}_{2}\right)$. To produce very narrow lines, a $\mathrm{SiON}$ filling layer was deposited after the formation of line trenches in the $\mathrm{SiO}_{2}$ dielectric. This was followed by $\mathrm{Ta}$ barrier and $\mathrm{Cu}$ seed deposition and $\mathrm{Cu}$ eletroplating. Then after Chemical Mechanical Polishing (CMP), SiNx and dielectric layers were deposited as capping layer and passivation to protect the $\mathrm{Cu}$ lines. The $\mathrm{Cu}$ lines used for this study were 850,185 and $60 \mathrm{~nm}$ in width, $110 \mathrm{~nm}$ in height, and $150 \mathrm{um}$ in length. Figure 1 shows the schematic layout of the sample.

(a)

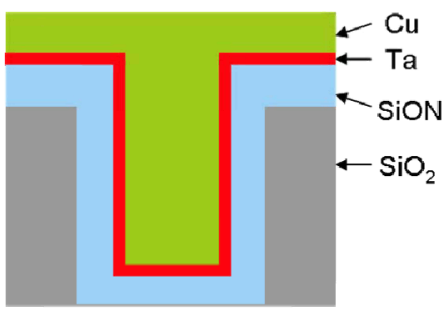

(b)

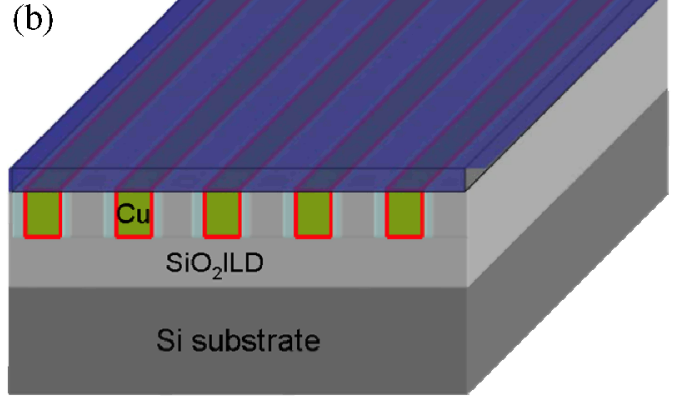

FIGURE 1. (a) Cross-sectional illustration of Cu trench with SiON filling. (b) Schematic of fabricated Cu interconnect sample.

Both plan-view (top view) and cross-sectional (side view) TEM samples were prepared to study the Cu grain structure along the $\mathrm{Cu}$ line direction. Figure 2(a) shows a schematic illustration of the sample. Planar TEM sample was prepared using a conventional method consisting of the following steps: 1) cutting out a $2 \mathrm{~mm}$ square specimen with $\mathrm{Cu}$ line structure almost at the center; 2) gluing the specimen to a $3 \mathrm{~mm}$ radius Ni grid (a single hole in the center) using M-bond 610 adhesive; 3) polishing specimen down to 100 um thick using the diamond grit paper. The specimen thickness was roughly controlled by using Gatan Disc Grinder; 4) dimple grinding specimen to approximately 5 um thick and 5) ion milling the specimen until electron transparency is reached using Gatan Precision Ion Polishing System (PIPSTM). The resulting TEM sample consisted of $\mathrm{Cu}$ lines confined with Ta diffusion barrier at both side walls. The top nitride passivation layer and bottom barrier layer have already been removed during the ion milling process. Figure 2(b) shows a schematic drawing of the plan-view TEM sample.

Site specific cross-sectional TEM sample was prepared using Focused Ion Beam (FIB) technique ${ }^{10}$. A $2.5 \mathrm{~mm}$ wide and $100 \mathrm{um}$ thick specimen strip was first prepared using the dicing saw. Before FIB milling, a $200 \mathrm{~nm}$ wide and $500 \mathrm{~nm}$ thick Pt strip was deposited on the target area to protect $\mathrm{Cu}$ lines from damage during ion milling. Then the 100 um-thick specimen was thinned from both sides down to less than 100 $\mathrm{nm}$ thick by using Ga ion beam. A FEI Dual Beam FIB equipped with an electron gun allowed the direct observation of the milling process. Final cleaning was done with $30 \mathrm{KeV} / 10 \mathrm{pA}$ beam to minimize beam damage to the target area. Figure 2(c) is an SEM image of one well-prepared TEM sample by FIB. TEM images were taken using JEOL 2010F and FEI TECNAI G2 F20 microscopes operating at $200 \mathrm{KeV}$. 


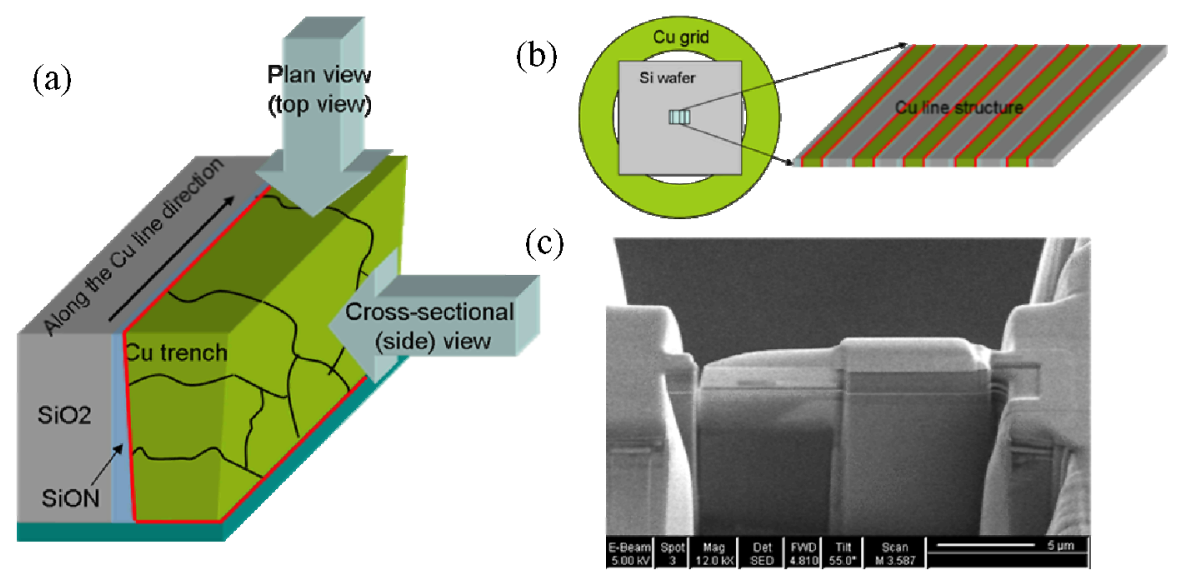

FIGURE 2. (a) Schematic diagram showing plan-view (top view) and cross-sectional (side view) observations of $\mathrm{Cu}$ interconnects using TEM. (b) Schematic drawing of the plan-view TEM sample. (c) SEM image of one wellprepared cross-sectional TEM sample.

\section{EXPERIMENTAL RESULTS}

\section{Plan-view (top-view) TEM Observation of Cu Line Microstructure}

Figure 3 shows the plan-view TEM images of $\mathrm{Cu}$ interconnects with line widths of (a) $850 \mathrm{~nm}$, (b) 185 $\mathrm{nm}$, and (c) $60 \mathrm{~nm}$. Distinct differences in the $\mathrm{Cu}$ microstructure can be observed for different line widths. While the $850 \mathrm{~nm}$ lines had both bamboo-like and multiple grain structures, the $185 \mathrm{~nm}$ and the $60 \mathrm{~nm}$ lines had predominately bamboo-like structures with the presence of microtwins. Statistical grain analysis on grain size distribution was carried out on the $185 \mathrm{~nm}$ and the $60 \mathrm{~nm}$ wide lines and the results are shown in Figure 4. The grain size was calculated as the diameter of the grain area by assuming the grain to be of circular shape. It shows that the average grain size scaled as the Cu line width decreased from 185 $\mathrm{nm}$ to $60 \mathrm{~nm}$. It is also observed that the narrow $60 \mathrm{~nm}$ lines had a higher population of small grains. This observation is consistent with the results reported in previous work ${ }^{9}$.

$850 \mathrm{~nm}$ line

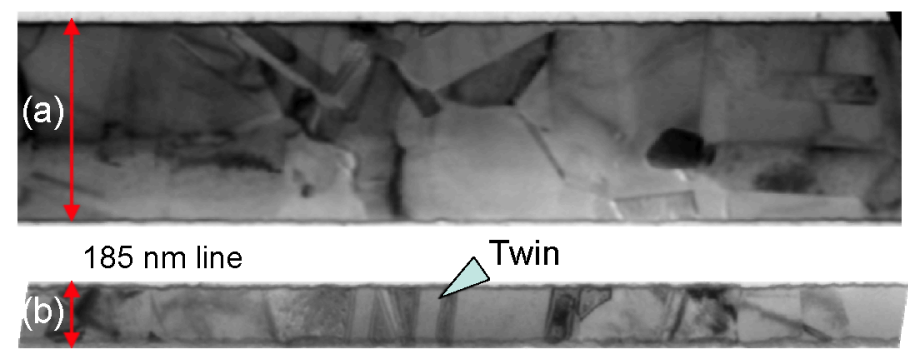

$60 \mathrm{~nm}$ line

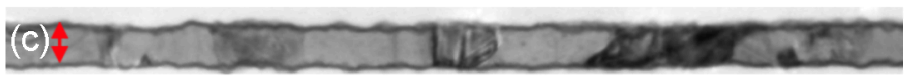


FIGURE 3. Plan-view TEM images of (a) 850 , (b) 185 , and (c) $60 \mathrm{~nm}$ wide $\mathrm{Cu}$ lines.

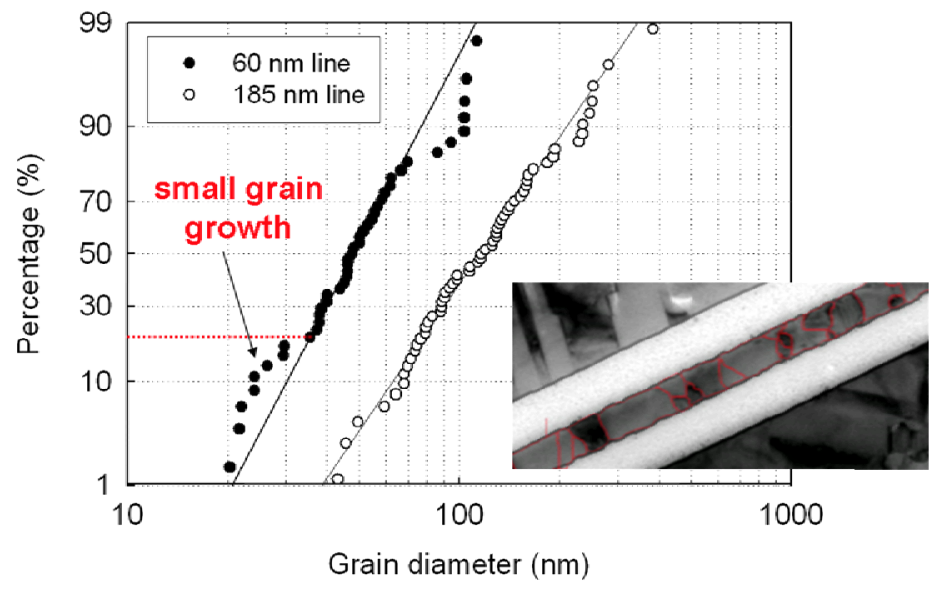

FIGURE 4. Grain size distribution of $185 \mathrm{~nm}$ and $60 \mathrm{~nm}$ wide $\mathrm{Cu}$ lines.

\section{Cross-sectional (side-view) TEM Observation of $\mathrm{Cu}$ Line Microstructure}

Figure 5 shows the cross-sectional (side-view) TEM images of $\mathrm{Cu}$ interconnects with line widths of 850,185 and $60 \mathrm{~nm}$. In Figure $5(\mathrm{a})$, the $850 \mathrm{~nm}$ lines show bamboo-like grain structures across the line thickness along the $\mathrm{Cu}$ line direction. In Figures 5(b) and 5(c), the $185 \mathrm{~nm}$ and the $60 \mathrm{~nm}$ lines have both polycrystalline and bamboo-like grain structures throughout the trench line. Some sections of the line were observed to have one single grain spanning the thickness, while other sections showed multiple grains across the thickness with more small grains at the trench bottom. No significant difference in the microstructures of the $185 \mathrm{~nm}$ and the $60 \mathrm{~nm}$ lines were observed in our study. However, narrower lines have been reported to have more small grains due to the larger proportion of PVD Cu seed at the trench bottom during $\mathrm{Cu}$ deposition which prohibited extensive grain growth to bamboo-like structure?
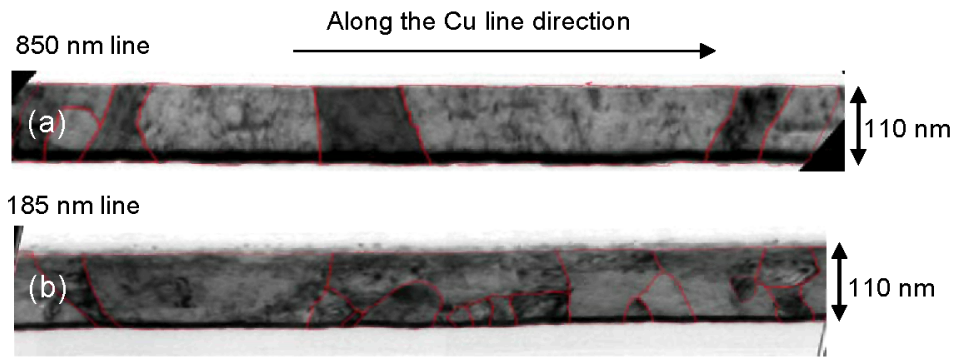

$60 \mathrm{~nm}$ line

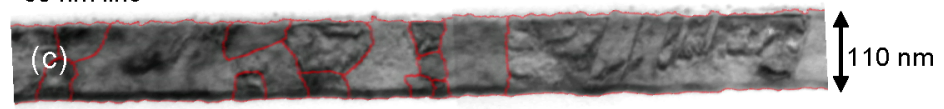

FIGURE 5. Cross-sectional TEM images of (a) 850, (b) 185 , and (c) $60 \mathrm{~nm}$ wide $\mathrm{Cu}$ lines. 
Grain growth in general is driven by minimization of energies, including that associated with the lattice, elastic, interfacial and grain boundaries. With scaling increasing the interface to volume ratio, interfacial pinning at the sidewalls and trench/via bottoms is expected to become more effective in anchoring small grains. This will favor the formation of small grains near the line bottom as the line width decreases, as observed in our TEM study. Since the distribution of the small grains is random, this raises an interesting and important question regarding the small grain effect not only on EM lifetime but also on the statistics. A higher fraction of $\mathrm{Cu}$ atoms at the grain boundaries and an increased number of fast diffusion paths will increase the void growth rate caused by EM and since the damage site depends on the small grain distribution, this in turn affects the EM lifetime statistics.

\section{CONCLUSION}

Ultra-narrow $\mathrm{Cu}$ interconnects were fabricated by damascene process with a trench filling of SiON layer and their microstructures were investigated. Both plan-view and cross-sectional TEM samples were prepared and investigated for $\mathrm{Cu}$ lines with line widths of 850,185 and $60 \mathrm{~nm}$. Plan-view TEM images showed that the $850 \mathrm{~nm}$ lines had both polycrystalline and bamboo-like grain structures. However, the $185 \mathrm{~nm}$ and the $60 \mathrm{~nm}$ lines had near bamboo-like grain structures. Statistical analysis of grain size distribution was performed and the results showed that compared with the $185 \mathrm{~nm}$ lines, the $60 \mathrm{~nm}$ lines had a larger population of small grains, which was attributed to scaling-induced small grain growth. TEM observation in the cross-sectional direction along the $\mathrm{Cu}$ lines showed that the $850 \mathrm{~nm}$ lines had bamboolike grain structure across the line thickness while the $185 \mathrm{~nm}$ and the $60 \mathrm{~nm}$ lines had a mix of multigrain and bamboo-like structures with more small grains at the trench bottom. The presence of excessive small grains in the ultra-narrow $\mathrm{Cu}$ trenches was attributed to the interfacial pinning of small grains and a larger proportion of $\mathrm{Cu}$ seed at the trench bottom. The scaling effect of grain structure on EM lifetime and statistics raises an interesting and important question for EM study of future $\mathrm{Cu}$ interconnects.

\section{ACKNOWLEDGMENTS}

This work was supported by Semiconductor Research Cooperation and SEMATECH Advanced Materials Research Center.

\section{REFERENCES}

1. D.N. Lee, MRS Symposium Proc. Vol. 427, 1996, pp. 168.

2. A. Gangulee, Journal of Applied Physics, Vol. 43, 1972, pp. 867.

3. C. Lingk, M.E. Gross, W.L. Brown, Applied Physics Letters, Vol. 74, 1999, pp. 682-684.

4. P. R. Besser1, E. Zschech, and et al., Journal of Electronic Materials, Vol. 30, 2001, pp. 320-330.

5. W. Steinhögl, G. Schindler, G. Steinlesberger, M. Traving, and M. Engelhardt, Journal of Applied Physics, Vol. 97, 2005, pp. 023706

6. K. Khoo, J. Onuki, et al., Japanese Joumal of Applied Physics, Vol. 45, No. 32, 2006, pp. L852 - L853.

7. K. Khoo, J. Onuki, et al, Materials transactions. Vol. 48, 2007, pp. 2703-2707.

8. K. Khoo, J. Onuki, et al., Materials transactions. Vol. 48, 2007, pp. 622-624.

9. C.-K. Hu, L. Gignac, B. Baker, E. Liniger, R. Yu, and P. Flaitz, IEEE International Interconnect Technology Conference Proceedings, 2007, pp. 93-95

10. D. H-I Su, H. T. Shishido, F. Tsai, L Liang, and F.C. Mercado, Material Research Society Proceedings on Specimen Preparation for Transmission Electron Microscopy of Materials IV Symposium, Vol. 480, 1997, pp. 105-116. 